Celebrity Studies. 7, 4, pp. 476-492:

http://www.tandfonline.com/doi/full/10.1080/19392397.2016.1233708

\title{
Everyday oracles: authors on Twitter
}

\section{Greg Myers}

Lancaster University

Most authors participate, reluctantly or enthusiastically, in a cycle of promotion, including book tours, literary festivals, interviews, and now social media. Some authors make regular use of Twitter to post updates about professional activities, comments on events in their everyday lives, news of readings, statements of opinions, photos, links, or retweets. This study examines tweets by ten authors, using corpus linguistic tools to find stylistic patterns characteristic of the corpus as a whole or of individual authors. It then looks at tweets by others that mention the authors or use quotations from the authors in new contexts, creating an on-line presence for authors whether they tweet themselves or not. Authors are subject to the same tension between ordinariness and specialness that others have noted with stars in music, television, or fashion. Literature, because of its assumed cultural position, and its production in private, is sometimes seen as being apart from and opposed to the cultural system of celebrity and promotion. But this cultural position also means the ordinariness of authors is treated as surprising and interesting, while the specialness makes them available to all as oracles.

Keywords: celebrity; authorship; everyday life; singularity; quotation, Twitter

\section{Novelists and celebrity}

In 'The Writer on Holiday', Roland Barthes explores the ideological contradictions between the everyday lives of writers, as represented in mass media, and their special status in high culture. A writer on holiday is doing just what salaried employees do, 
taking some time off from work, and yet he or she is still a writer, not a salaried employee. A writer remains special, distanced, inaccessible, as 'a kind of intrinsically different being which society puts in the window' (p. 30). The reports in the mass media (a photograph of André Gide in Le Figaro, in this case) that show that writers continue to participate in the everyday (reading on holiday, or in Barthes' other examples, wearing blue pajamas, or liking reblochon cheese), only reinforce their special creative or philosophical status.

Barthes is fascinated by the mediated image of the author (or in other essays in the series, Einstein or Garbo) as a celebrity. From the many definitions of celebrity (e.g., Dyer 1979, Braudy 1997, Rojek 2001, Turner 2004), the aspects most relevant to this study are that celebrity is an embodied performative practice, merging the ordinary and extraordinary, involving mediated audience practices, developed through a historical process, with the same sorts of processes applying along a continuum. Authorial celebrity is a performance, in the sense of Goffman (1959) that celebrities present themselves as famous to a wider world (Marwick \& boyd 2011). It is an embodied performance in that the usually invisible author is made visible in photographs, videos, and personal presence (Gamson 2011). This performance paradoxically must include signs both of the extraordinary (talent, beauty, wealth, or specialness) and the ordinary, the physical body and daily life that make the celebrity potentially accessible (Dyer 1979). Celebrity is also a set of cultural practices by audiences, 'the attribution of glamorous or notorious status to an individual within the public sphere' (Rojek 2001, p. 10). These cultural practices require mediation, including the press, film, music, and broadcast media, but also social media and even personal appearances in readings and festivals. Especially in the last fifteen years, with the rise of social media, celebrity has been seen as a continuum 'a set of 
circulated strategies and practices that place fame on a continuum, rather than as a bright line that separates individuals' (Marwick \& boyd 2011). Microcelebrities with sometimes tiny audiences share with the stars at the other end of the continuum the orientation to popularity, the management of a fan base, and the presentation of themselves in ways that make their easy to consume and circulate (Senft 2008, Marwick \& boyd 2011).

The processes that apply to stars of music and reality television and to the microcelebrities of Youtube also apply to figures for whom there is a narrower but still intense kind of fame, among mathematicians, or folk musicians, or on-line gaming enthusiasts - and, as Ohlsson, Forslid, and Steiner (2014) argue, novelists and poets. The fame of literary figures has often been seen as problematic, a blurring of the boundaries between high culture and low (Wicke 1988, Gamson 2011, Ommundsen 2009 have all noted these criticisms). But such fame is not new; figures such as Sterne, Byron, or Wilde were celebrities in the $18^{\text {th }}$ and $19^{\text {th }}$ centuries (Braudy 1986, Moran 2000) and Nobel Prize winners often are today (Braun 2011). Being a celebrity is not the same as being a commercial success; as Moran (2000, p. 6) points out, the authors who sell the most books (such as Danielle Steele, Michael Crichton, Tom Clancy) are not the same as those who are reviewed, given prizes, and taught in universities, and it is the latter group who have more use for, and are more used by, the practices of celebrity.

Of course this continuum of celebrity is still relative. There are no authors in the list of the 100 most-followed accounts on Twitter (@jk_rowling has about 8 million followers; @ katyperry has about 92 million), and most of the authors I will discuss have between 10 thousand and 100 thousand followers, that is, a thousandth of those for the most followed accounts. Only a few novelists reach the levels of 
general celebrity where their faces are widely recognised, their every pronouncement is news, and they cannot walk down the street or go to the supermarket for milk without attracting attention (examples might be Ernest Hemingway, Salman Rushdie, J. K. Rowling, and recently George R. R. Martin). But successful authors, of both literary novels and more popular genre novels, have communities for whom they are magical, people who want to know almost anything about them, people who will queue for long hours for their 30 -second interaction at a bookstore signing. The process involves attributing to the celebrity a special status, what Leypoldt (2014) calls 'singularity', and what I am calling an oracular persona. Their names and images appear on the advertisements for literature festivals or creative writing courses, exactly like the acts in a music festival, so you know you should have heard of them even if you haven't. The newspaper review sections and on-line blogs ask them about their reading, their pets, and yes, their holidays. Film stars and pop stars are also pressed to reveal the ordinary person underlying the star persona (Dyer 1979, Petersen 2009, Kehrberg 2015); the difference is that authors may be seen as compromising what has been seen as an essentially private practice.

Paralleling this tension between the author as a private voice and the author as a public celebrity is a tension between the reader as an individual, caught up in the book, and the reader as part of a social group, all relating to the author and potentially to each other. Images of readers, for instance in the photo-essay by Andre Kertesz (1983), show them curled on a sofa, or in bed, or on a crowded subway oblivious to those around them, and that isolation and concentration is one aspect of reading practices. But one line of literary study has also stressed the social nature of reading (for a review, see Swann and Allington 2009), as shown for instance in the practices of book clubs (e.g., Long 2013), community reading projects (e.g., Bérubé et al. 
2014), on-line book sites (e.g., Vlieghe et al. 2016), and literary festivals

(Ommundsen 2009). The solitary experience emerges from and goes back into a social process of reading with other readers as a community brought together by shared recognition of something special to them in the book.

Social media such as Twitter offer new modes of interaction between writers and readers, but not entirely new forms of celebrity; Sarah Thomas suggests that the newness of new media is in 'how Twitter renders constructive processes visible and available' (2014, p. 244). The same sorts of processes were going on in Dickens' public readings or Hemingway's photos, but now we see them worked out, and timestamped, moment to moment. Social media can also cut out the intermediaries (Marwick \& boyd 2011), the layers of publicists and reporters (or in the case of authors, publishers and reviewers) that have traditionally done the work of producing the right mix of the ordinary and extraordinary for noted authors. The author herself or himself might post their holiday photos, or tweet about a public reading or a book signing, a walk in the woods, being stuck on a train, staying up late to watch a movie on DVD, making dinner, or watching their cat.

Reading beneath bougainvillea, crow, pre-sunset moon. \#Karachi (@KamilaShamsie, 5:08 AM, 24 February 2015)

This morning's commute has been as boring and endless as an anecdote told by a pothead. (@Patrick_Ness, 1:39 AM, 27 February 2015)

But their claim to attention, the specialness that makes the ordinary worth attention, is always based on their having written the books. Readers may post quotations from authors, or their pictures, or news of their events, all constructing the authors as special. They may compare responses with other readers, or identify themselves with favourite authors. The processes of building up (and sometimes tearing down) an 
image for the author that once took place backstage in publications, or in conversations, now take place in public.

Though early celebrations of Twitter and other social media suggested they could become a way of democratising fame and making the famous more accessible, studies of celebrity on Twitter have shown that it assumes and reinforces the asymmetries of access (Marwick \& boyd 2011, Thomas 2014). Stars have many followers and follow few. Fans bid for the attention of stars (Kerhberg 2015). Updates may be addressed to a broad audience ('for-anyone-as-someone' as Paddy Scannell (2000) described the form of address in broadcasting). But responses to direct messages, or retweets of material form others, are carefully doled out, and indeed, anyone with even 90 thousand followers, much less 90 million, would find it impossible to respond to all the demands on their attention and recognition.

I will study a collection of tweets by focusing on some linguistic choices that are shared by a group of authors, and other choices that make them different from each other. I use corpus linguistic techniques to identify features for further study, and then analyses examples from concordance lines to see whether these features relate to the tension between everydayness and singularity that I have been discussing. There have been extensive corpus studies of literary texts (e.g., Mahlberg 2013; Hoover et al. 2014), focusing on such issues as characterisation, reported speech, and authorship identification. They can usually take a canonically (if controversially) bounded set of texts, such as the novels of Dickens, as a starting point for analysis of patterns we might miss without this overview (for instance, Mahlberg's (2010) attention to the Dickens narrator's interruptions in characters' reported speech).

Tweets, by authors, or anyone else, require a somewhat different approach from novels; they are part of a stream of small units across time, interspersed with, 
replying to, and retweeting other tweets, incorporating photos, videos, and music, linking to web sites including blogs, news stories, and campaigns, and depending for their meaning on all these other texts. Corpus linguistic tools are still essential because they challenge the sometimes misleading impressions we might get from reading individual tweets, making us consider a collection of texts (even if it is still a relatively small one). Ruth Page (2012a) has used corpus tools to study the differences between tweets from celebrities, ordinary users, and organisations; I am using the same tools to find distinctive features of one kind of celebrity tweet, those by authors.

I will consider first how the tweets by a group of authors are like or different from other writing and other tweets, and at ways the tweets of one author are like and different from those of other authors, focusing on the ways that they present themselves as accessible to readers, and on a stylistic tendency to elaboration. Then I will consider how these authors are tweeted about, by others, both in comments on their work and, something I had not noticed before, the circulation of quotes. The authors' own tweets tend to emphasize what they share with readers in their everyday experience, to the point where readers treat them as instantly accessible. The tweets about authors tend to distance them again, treating them as providers of general and reusable wisdom. As Barthes points out, both the everyday and the oracular contribute to the process of construction of a celebrity figure for the writer: 'To endow the reader publicly with a good fleshly body, to reveal that he likes dry white wine and an underdone steak, is to make even more miraculous for me, and of a more divine essence, the products of his art' (1957/1972, p. 31). 


\section{Data and methods}

Studies of Twitter often use very large sets of data, gathered through the Twitter API (Application Programming Interface). ${ }^{1}$ My corpora are very small; larger sets would allow for much more complex statistical analysis, but here I am using the corpus analysis as a heuristic to lead to more qualitative analysis of the tweets in context. I systematically collected tweets from ten authors, starting from the end of August 2015 and going back and forwards as necessary to get 100 for each. Several concordance tools are available to find patterns in a corpus; I use Wmatrix (Rayson 2008) because it also gives frequencies for Part of Speech categories. ${ }^{2}$ I built my corpus, not to represent literature in general, but to include a range of different kinds of authors who might have different kinds of relations to their audiences. One obvious bias is that I chose authors I had read, because I need to know how these tweets relate to their novels (this may also explain the bias towards British or British-American authors). I wanted authors who 1) tweeted often (not J. K. Rowling), 2) were still tweeting (not Teju Cole), 3) had at least 2000 followers, and 4) usually tweeted their own messages, not just retweets of others (not Neil Gaiman). Within these criteria, I chose authors from three categories:

- well-established winners of literary prizes (Oates, Kennedy, Rankin), so that we can relate their online presence to the attention they get from established literary reviews

- authors who have been taken up by what is called a 'Young Adult' audience, even if they also or always write for other audiences (Dunthorne, Ness, Pullman, Rosoff), since younger audiences are especially familiar with social media 
- authors named in Granta's most recent 'Best of Young British Novelists' list

(Fagan, Selasi, Shamsie), since younger authors seem to be more likely to use Twitter as a regular part of their practice

Of course, these groups may overlap. The list that resulted is as follows (with numbers of followers in August 2016):

\begin{tabular}{|l|l|l|l|}
\hline Writing name & Twitter name & Followers & Examples of novels \\
\hline Joe Dunthorne & @joedunthorne & $10.7 \mathrm{~K}$ & Submarine \\
\hline Jenni Fagan & @ Jenni_Fagan & $3.7 \mathrm{~K}$ & Panopticon \\
\hline A. L. Kennedy & @ writerer & $12.9 \mathrm{~K}$ & Day \\
\hline Patrick Ness & @Patrick_Ness & $43 \mathrm{~K}$ & Chaos Walking trilogy \\
\hline Joyce Carol Oates & @ JoyceCarolOates & $149 \mathrm{~K}$ & them \\
\hline Philip Pullman & @PhilipPullman & $47.5 \mathrm{~K}$ & His Dark Materials \\
& & & trilogy \\
\hline Ian Rankin & @beathhigh & $101 \mathrm{~K}$ & DI Rebus crime novels \\
\hline Meg Rosoff & $@$ megrosoff & $7.4 \mathrm{~K} *$ & How I Live Now \\
\hline Taiye Selasi & @ taiyeselasi & $11.6 \mathrm{~K}$ & Ghana Must Go \\
\hline Kamila Shamsie & @kamilashamsie & $17.3 \mathrm{~K}$ & A God in Every Stone \\
\hline
\end{tabular}

*Followers in September 2015. Rosoff is now off Twitter.

Writers do what other users do with Twitter, posting short comments on what is happening, yes, but also photos of events, links to news articles or videos, on which they comment, retweets of messages that interest them, with or without comments, and replies to people who have tweeted them directly, often with questions, or mentions of others whom they want to promote or address. The authors are very different from each other. Dimensions of difference include continua between: 
- those who mostly tweet in their own voice (@PhilipPullman) and those who mostly retweet (@MegRosoff)

- those who engage in conversations (@Jenni_Fagan, @JoeDunthorne) and those who mainly put out freestanding tweets (@beathhigh, @writerer)

- those who prefer text (@ JoyceCarolOates) and those who more often use pictures and links (@taiyeselasi, @Jenni_Fagan, @JoeDunthorne)

Authors who have larger numbers of followers, and who are known to campaign on certain causes (@JoyceCarolOates, @beathhigh, @PhilipPullman), are often asked to retweet to get some message to a wider audience. They do, as one would expect, promote books, their own and those by others, usually by links to events. But they also have consistent interests in culture more generally and in politics, music, beer, or cats, rather like other people on Twitter.

I could have started just looking at lists of the most frequent words and parts of speech. But this would be unlikely to be illuminating, since the different corpora have similar sets of most frequent words, starting with the and some prepositions and conjunctions. So corpus analysis often uses keywords, words that stand out as relatively frequent in one corpus as compared to another. Mahlberg (2010) gives the example of the relative frequency of civility in the work of Jane Austen. For a general reference corpus of English writing, I used the British National Corpus (BNC) written sampler, with selections from across many genres. I also collected a reference corpus of tweets by non-authors, people interested in such fields as wine, dogs, or teaching. ${ }^{3}$ For instance, the article the may be frequent in almost any English corpus, but one corpus may use it relatively much more than another, which could prompt questions (as we well see later) about whether one has more definite noun phrases, or perhaps whether another is more likely to delete the article. I compare the whole set of tweets 
by ten authors to the BNC written sampler, to see some features of tweets as a genre, and then to the reference corpus tweets by non-authors, to see how authors might use Twitter differently. But the ten authors are different from each other, so I also compare the tweets by each writer to a reference corpus made of tweets of the nine other tweets by writers, to see if it tells us something about what makes this writer distinctive.

One way to measure the statistical significance of a keyword, the possibility that the preponderance in one corpus over another was not due to chance, is by a calculation of log-likelihood (LL). ${ }^{4}$ When a word has a LL above 15.13 and is relatively frequent (over about $0.5 \%$ of the total) I look at a concordance of all the lines in which this word occurs, to see how the author is using it. I tend to focus on grammatical function words, which are frequent even in a small corpus and which can serve as cues to significant stylistic differences.

The point of bringing corpus analysis to celebrity Twitter studies, as it was brought to literary analysis, is that it can show underlying differences in linguistic choices that might not be apparent just in casual reading. Differences can get lost in the apparent similarity of tweets; similarities can get lost in the more obvious differences in personal styles.

\section{Authors use Twitter style}

I first compared the Author Twitter corpus to a standard set of writing in English across a range of genres, to see how Twitter, as used by anyone, might be distinctive. Some of the terms over-used in the Twitter corpus would be expected, including Twitter and tweet, which did not exist when the BNC, my reference corpus, was compiled in the 1990s, and http and online, which were not used then outside of technical discourse. The most striking set of keywords is around the first person 
pronoun: I (LL 235), my (LL 121), and the related form of the verb to be, ' $m$ (LL 102), and am (LL 49). To acknowledge the obvious, tweets are mostly in the first person (though we will see come complexities when we discuss individual authors).

I heartily recommend All My Puny Sorrows by Miriam Toews: bleak as hell, blunt, v. funny. (Ignore the bad cover.) (@joedunthorne, 12:43 PM, 31 May 2015)

You, though frequent with 134 instances, is not a keyword, because it is frequent in the BNC too. (Purohit et al. (2013) discuss the use of pronouns in Twitter).

Two other clusters of keywords in comparison to a general corpus of writing are related to this first-person perspective. Some keywords, such as just (LL 63) or today (LL 57), convey the sense of immediacy in on-line interaction:

Just watched Liam Neeson in TAKEN (@PhilipPullman, 2:58 PM, 27 July 2015),

Recording an interview today and worried about my hair. It's a radio interview. Sigh. (@Patrick_Ness. 1:35 AM, 21 August 2015)

And there is another cluster of keywords around strong evaluations, such as great (LL 61) and love (LL 39).

Great, smart piece here... (@writerer, 7:12 AM, 20 July 2015) this man's dazzlingly encyclopedic knowledge + infectious love of literature (@taiyeselasi, 9:22 PM, 21 May)

(Love is applied 7 of 20 times to something non-human).

The comparison of the tweets to the written sampler gives rough, and not very surprising, results, but the overall picture we get is one of tweets stressing interaction, immediacy, and stance-taking. These features do not tell us about the way authors are different as celebrities, but about the ways that they use Twitter like anyone else. 


\section{Authors index a shared world}

When we compare the Author Tweet corpus to the reference corpus of tweets by those with other interests, we see some hints of how they are different as authors from other users of Twitter. First, we would expect that the authors use more of the words associated with their trade: novels, books, fiction. And they do. The important differences are not in vocabulary, but in the construction of their tweets. In this section I will focus on a keyword and some key classes that can be interpreted as showing elaboration and specificity, contributing to the sense of our sharing their world.

One keyword that links to a sense of a shared world is the definite article the (LL 97); again the point is not that it occurs frequently (it does in most samples of English text) but that it occurs more frequently in Author Twitter than in the reference corpus. There are two possible reasons to discount this over-use. Many of the instances in the Twitter corpus are accounted for by the authors' frequent use of titles, which very often start with a definite article, as in this anecdote:

In Waterstones. Bookseller: You've come for the blood of Olympus? Man: No I've come for the house of hades. (@joedunthorne, 5:54 AM, 27 March 2015)

Another reason authors may over-use the is just that they are less likely to drop it. Biber et al (1999, p. 363) note that the article can be omitted in 'block writing' such as headlines, and it seems to be dropped more frequently in the Reference Corpus to save space: 'Now we're finishing off wine' (instead of the wine). The definite article seems to indicate a preference for slightly more formal prose (authors also tend to spell out and instead of using \&).

But use of the also has other stylistic effects that may affect the relation of readers to the authors. Biber et al. (1999) note that one of the less noticed uses of the 
definite article is 'to reflect the shared situational context of the speaker and hearer' (1999, p. 264). This sense of shared context is part of what makes the ordinariness so vivid. Consider this example:

The organ guy is playing later than usual on the beach tonight, he's really going for it. (@jenni_fagan, 10:21 AM 4 July 2015)

Readers who do not live in the Portobello area of Edinburgh may not already know whom she is talking about, but by saying 'the organ guy' she brings us into her situation and presents him as shared knowledge. (As Biber et al. note, such uses are a common device in fiction (1999, p. 265)). Purohit et al. (2013) see the definite article as a potential indication of conversational engagement in Twitter; in short texts, the anaphoric reference is likely to be something mentioned in another tweet. But the referent may be marked as given, rather than new, to produce a sense that this is something already known and shared.

The definite article (and demonstratives) may mark something more conceptual but still, it is suggested, recognisable by the reader:

Really liked 'It Follows' last night. That warm feeling when you leave the cinema and believe every stranger on the street wants to kill you (@joedunthorne, 7:58 AM, 24 March 2015)

Dunthorne is telling us about his own experience of the movie, but 'the cinema' and 'the street' evoke a shared feeling. This kind of shared experience is part of Marwick \& boyd call performative intimacy (2011, p. 148) in celebrity tweets. Of course it isn't just celebrities who share experiences; after all, the current prompt for a Twitter update is 'What's happening?' But when a celebrity does it, it amounts to an invitation backstage. My point about authors is that they are more likely to make this kind of move with the simple device of the definite article. 


\section{Writers take stances cleverly}

Tweets can perform intimacy and suggest affiliation by saying where the writer is and what they are doing. They can also do affiliation by taking a stance, that is, by stating or implying an evaluation of something. Of course anyone on Twitter can do this; it is almost all stances. Bu these authors are distinguished by how they do it. Wmatrix automatically tags text in the corpus for word class. ${ }^{5}$ Authors use more general adverbs (LL 74.23) and general adjectives (LL 48.16). In both these categories they also have a wider range of words, not just using a few of them frequently. To give an idea of this range, here are some examples of words that I chose from the long list of those used only once in the Authors Twitter corpus.

followed by dreadfully civilised comments (@joedunthorne, 6:51 AM, 10 April 2015)

it's just one more thing to be unnecessarily annoyed about. @ philippullman, 2:11 AM, 16 June 2015)

Husband orders myriad items from Amazon delivered w/ dazzling swiftness then lying unopened in kitchen for days, weeks. (@joycecaroloates, 11:35 AM, 16 August 2015) it's more just a kind of unvarying measuredness that I'm resisting. (@ patrick_ness, 4:21 AM, 21 August 2015)

As John DuBois (2007) has argued, stance-taking involves interaction - one takes a stance about something in relation to someone else. In these examples, the unusual modifiers add intensity or wit, and sometimes a sense of shared culture with the readers, people who would themselves say 'myriad' rather than 'lots of', or who would undercut 'civilised' with the mocking 'dreadfully'. The projection of shared stances is a more subtle way of doing what Marwick and boyd call affiliation, 'the process of publicly performing a connection between practitioners and fans using 
language, words, cultural symbols, and conventions' $(2011,147)$. Of course the same sort of vocabulary could put other readers off, but these are not the readers who follow these authors or read their books.

\section{Some differences between authors}

The keywords so far are for the whole corpus of authors, compared to a reference corpus. But unsurprisingly, with such a wide range of authors, that they are very different in their styles on Twitter as well as in their novels. To find these differences, we can compare each set of tweets to all the others. Some keywords for individual authors reflect the content of the tweets, so no one who knows their interests will be surprised to find such keywords as nature, for @ joycecaroloates, Edinburgh, for @ beathhigh, or cricket for @ kamilashamsie. Other features suggest different strategies in the ways they engage with followers.

Other keywords may point to less obvious differences in style between the writers. I have referred to the use of the definite article; more than a fifth of these occurrences are by @ philippullman. However, his corpus actually features a fictional narrative over many tweets, which includes many of the situational uses I have discussed. It is striking that two of the authors, @joedunthorne and @ patrick_ness, together account for more than a third of the uses of $I$ in the corpus. But it would be a mistake to jump to the conclusion that this is an indication of egotism or self

reference. Seven of the 60 used by @ joedunthorne are in reported speech and refer to other people, and only 9 are present tense actions or stances (I read, I declare, I recommend, I approve); more of them are announcements of events in which he is participating. There are more that are present tense reports of what @ patrick_ness is doing or thinking (about half of them) but he also has a lot of announcements of 
events (he was on tour part of the time) and his total is especially high because he has a list of ten tweets of the form 'I write because'.

The comparisons of authors' use of I emphasizes the point made earlier, that the pronoun is not usually necessary in tweets. Differences in numbers may indicate more or less dropping, rather than differences in self-reference. Here are some examples from @ Jenni_Fagan, who uses $I$ less than the other writers.

Just wrote the longest poem, 1777 words, ridiculous length but I like it. (8:07 AM, 27 August 2015)

Poured a bath, got distracted, spent 3 hours writing poetry, now going to have to drain a cold bath — nowt poetic about that. (2:21 PM, 13 August 2015)

Can't wait to go and see this [The Magic Flute] (11:58 PM, 5 August 2015)

Some time to focus solely on my poetry. It feels like coming home. (4:39 AM, 13 August 2015)

Long walk in the rain, huge mug of tea. (2:53 AM, 14 August 2015)

Earache. Glass of wine. Editing. Trying not to move house. (2:07 PM, 3 August 2015)

All these tweets report personal experiences but drop the $I$ (as in the first three) or both the subject and the verb (as in the next three), without any confusion of reference. Another way she conveys personal experience is just by posting a photo: a sunset near her house, a beach scene from a holiday, other authors at a book signing. One does not need to use a pronoun to suggest a first-person point of view and a glimpse backstage.

The previous section showed that authors, as a group, have strategies for performing intimacy (uses of definite noun phrases) and inviting affiliation (unusual stance-taking). This section suggests that, as one might expect, the authors differ in the ways they engage with followers, and that they do not converge on one set of devices. Or to put it another way, they are similar in all adapting, one way or another, 
to the constraints and affordances of Twitter, but they remain recognisably different in what they do within these constraints.

\section{The readers tweet back}

Of course the author is not the only one who tweets about their work; readers will tweet about them. In general, they are not calling for responses or retweets from authors, as do fans of the most popular Twitter celebrities (Kehrberg 2015). I have searched the first 100 recent tweets that include the names of each of the authors in my corpus; I will present some examples for just one author. One common form of tweet reports progress in reading a book, often via Goodreads.com:

3\% done with A Monster Calls, by Patrick Ness (Meidu @ Mridu2903, 1:38

PM, 13 September 2016 - Twitter post)

Here is a series of posts from one reader on Goodreads.com on Ness's novel $A$ Monster Calls; each generates a tweet from Marion@ IlliterateBlog:

Marion is on page 52 of 206

This is going to break my heart, isn't it? - Sep 14, 2016 10:59AM

Marion is on page 168 of 206

Okay. I'm crying. I don't like this. - $\underline{\text { Sep 16, } 2016 \text { 08:39AM }}$

Marion is finished

Alright. Let me wipe my tears and process this, and I'll get back to you... $\underline{\text { Sep 16, } 2016 \text { 09:08AM }}$

The underlined time is a link to the post, and if one is also registered on Goodreads, the underlined name leads to the reviewer's profile. Some tweets by readers amount to mini-reviews within the constraints of Twitter. 
Finally sat down and read through A Monster Calls today. That book hit me hard and all at once. Incredible writing. Thank you@Patrick_Ness (Kambo, @kc_sloan, 6:13 PM - 16 September 2016 - Twitter post)

This reader seems to be considering reading the novel, not reviewing it:

the knife of letting go by patrick ness got almost 4 stars in goodreads Well hm hm (bookurchin @ HailHermoine, 7:31 PM, 15 September 2016 - Twitter post)

Some mentions come up in the course of other internet conversations, such as a running joke inventing puns on cheese in book titles:

A Muenster Calls \#PatrickNess \#cheesebooks (Diana @ robotgenius, 2:40 PM, 15 September 2016 - Twitter post)

Note that only one of these actually addresses @ Patrick_Ness, with a possibility of a response from him. There are also reports of book groups, comments on interviews and appearances, controversies about something the author has said, questions for school reports. (I did not find any tweets of sightings in public, which happen with many celebrities. But only three or four of the authors in my corpus have well-known faces). Some of this attention may give the author a satisfying feeling of connection to an audience, while others may be almost bullying. Authors are caught up in a stream of social media attention whether they participate or not.

Of course this sort of attention to writers by readers has a long history Dickens famously complained about it (see Dickens 1842). But social media makes it more than the occasional encounter with a reader; it is an insistent, unavoidable, and public stream (Ommundsen 2009, Gamson 2011, York 2013). One can say, as many authors do, that you don't read reviews, but if you are on social media yourself, you 
will see these good and bad comments, as well as outright abuse. In summer 2015, the author Joanne Harris gave a talk in Manchester presented as 'A Writer's Manifesto'. She started with the effects of social media on writing practice: 'audience participation in the creation of art is considered by many to be not only legitimate, but desirable'. She then went on to make a dozen 'promises' in response to these reader demands, two of which are below:

9. I will never let anyone else decide what I should write, or how - not the market, my publishers, my agent, or even you, the reader. And though you sometimes try to tell me otherwise, I don't think you really want me to. 10. I promise not to be aloof whenever you reach out to me - be that on social media or outside, in the real world. But remember that I'm human too - and some days I'm impatient, or tired, or sometimes I just run out of time. (Lea 2015)

Almost any writer would agree with Number 9, and it is a sign of the pressure she feels that she would even need to say it. Number 10 makes a promise that many other writers would not want to make. We have seen that A. L. Kennedy is active on Twitter. But even she, when asked by the Guardian, had her doubts:

If you're not that sociable, then it's hard to fake sociability. I know some authors who would be their own worst enemy if they had to be very outgoing in certain contexts and who avoid them like the plague as a result (Lea 2015).

Kennedy raises the same issues of sincerity and authenticity that Trilling (1972) raised about Romantic literature, and Marwick and boyd (2011) applied to celebrity tweets. Like celebrities in any field, authors may find it hard to negotiate the terms on which attention is paid to them (2001). But the tension is perhaps greater for authors, because they do not need to be 'outgoing' to produce their art, and where some views of their calling oppose it to popular culture (Braudy 1997). 
Just in the time I have been writing this paper, three authors in my corpus have been subjects of mass media attention, positive or negative, to their social media activities. Meg Rosoff was widely attacked (and defended) for her comments on calls for children's books with characters representing marginalized social groups (Flood 2015). Joyce Carol Oates was widely criticized for a provocative tweet (typically for her, in the form of a question) (Victor 2015). And Patrick Ness was widely praised for raising more than $£ 200,000$ for refugees in one day with a tweet promising matching donations (Crown 2015). Social media seem to have reduced the distance between writer and public, and between the literary figure and popular culture. Or rather, to follow the point quoted earlier from Sarah Thomas. Social media have made 'more visible and available' (2014) the constructive processes, and the tensions between the ordinary and the special that have long been part of authorship.

\section{Oracles}

Even in this social media terrain, writers keep some aspects of their special status. One of the processes in which any author is likely to be involved, whether they participate in social media or not, is the circulation of what are called 'quotes', texts or images giving a short passage that is presented as having general application, or as being specifically applicable to a new context (see Nakamura (2013) and Rowberry (2016). This practice is not, of course, new; for hundreds of years there have been commonplace books, dictionaries of literary quotations and a whole segment of publishing devoted to anthologies of reusable passages, 'jewels' or 'beauties', from the work of Shakespeare, Ruskin, or George Eliot (Price 2000, Morson 2011). What has changed is the breadth and speed of on-line comments, so even the most recent books can have quotes circulating throughout Twitter and other media. 
I was surprised to find that each of the ten writers in my collection has some quotes that take on a life separate from their original sources. Writers are seen as sources of wisdom, speaking outside and beyond their works, as authorities on writing and life. Oates and Shamsie, for instance, are recent graduation speakers. (I see @joedunthorne gets a tweeted request for 'some words of \#inspiration' to share with fellow students, as if he wrote such quotations, rather than novels). When a quote is taken from an author's fictional works rather than their public statements in their own name, it involves creating a second (or third or fourth) speaker. In the world of 'quotes', authors merge entirely with other celebrities; the same Twitter feed could have the words of Maya Angelou and then Taylor Swift.

To function this way, the quote has to be stripped of the speaker and hearer, intentions, and surroundings of the original utterance, and recontextualised. Consider, for instance, this quote from Ian Rankin's Exit Music (2007).

"It seemed to him a very Edinburgh thing. Welcoming, but not very." — Ian Rankin

For those who recognize the name of the author, it is clear that the he is not Ian Rankin, but Detective Inspector Rebus in the close third-person narration characteristic of this series of novels. As is usual in a detective novel, the setting tells us something about the character. Rebus has just gone into the flat of a woman he is about to interview, and he is noticing a feature of the layout, the 'dining hallway' that allows guests to come in without actually entering the living room. But in its quoted form, the 'very Edinburgh thing' becomes a general comment on the attitude of the population, reusable in other contexts.

Some quotes come from contexts in which they were already statements of general truths, so not much change is made in excerpting them and attributing them to 
the author. One could imagine that Philip Pullman's His Dark Materials would be fair game, since it has quoted epigraphs to its chapters. And it does provide quotes for others:

All the history of human life has been a struggle between wisdom and stupidity. - Philip Pullman

Pullman, who is not shy about commenting on wider cultural issues, could make a similar statement in his own voice. But in this form, it comes from near the end of The Amber Spyglass (2000), where the witch Serafina Pekkala is explaining to Mary, the scientist, and Lyra how she found the gap between the alternative universes. Mary then agrees that it is true of her (and our) world.

Whenever there are first or second person pronouns in the source, the transition to general quote requires more radical recontextualisation. One of the most frequently-repeated quotes from any of my authors is from Joe Dunthorne,

I love you more than words. And I'm a big fan of words. - Joe Dunthorne, Submarine

Here the words start with an allusion to a song by Booker T. Jones and Elvin Floyd (most famously sung by Otis Redding), either by Oliver or by the author or both. In the novel, Jordana is having Oliver write out the imagined entry for this day in his diary, while she reads them. He writes 'I love you more than words. And I'm a big fan of words'. But the next words he writes in the diary are, 'This was a cheesy thing to say, but being in love with Jordana, I have discovered, tends to make me cheesy.' So the words are 1) imagined, 2) written out, 3) read by the real recipient of the imagined words, 4) evaluated by the writer commenting on his own imagined speech, and 5) this retraction is used as a further indirect address to the reading Jordana. But 
all this is stripped away when it becomes a quote; it becomes a generic profession of love, followed by a fairly nerdy self-assessment.

A quote from Patrick Ness has taken on a similar life of its own in business tweets:

Being a leader is making the people you love hate you a little more each day Patrick Ness \#quote

In these tweets it is offered as general wise advice on leadership. In the source, The Ask and the Answer, second volume of the Chaos Walking trilogy, it is a quotation of a quotation. Viola, the young heroine, is being treated in a healing community and is asking the woman dressing her wounds about Mistress Coyle, who resigned from a role on the town committee. The carer says:

"She's always saying that being a leader is making the people you love hate you a little more each day." She catches my eye. "Which is something I believe, too." (Ness 2009)

Mistress Coyle, as represented in the novel, is heroic but complex; she is not offered as a model leader for every organisation, and it would be a less interesting book if she were. Out of context, it just reassures any unpopular leader; no wonder it is used so often.

If one wants a quote for a tweet or a poster or an epigraph, one does not actually need to read the book to find such quotes; all of those I have used as examples turn up in such sites as goodreads.com, brainyquote.com, and quotegarden.com. It is a principle of these sites that every book has quotes in it. There are also other sites, such as quoteinvestigator.com, that correct misquotations. Quotes circulate in quote-of-the-day sites, quote tweet bots, as epigraphs in blogs, on t-shirts, mugs, aprons, and tattoos. They are like proverbs or maxims, applicable by anyone to 
any situation, but in the case of quotations, the name of the author is always attached and lends some cultural authority. Of course it is not just authors who are mined this way; one can find quotes from sports stars, religious leaders, bosses, and all sorts of historical figures. The difference, perhaps, is that sports stars are quoted because they are celebrities, while authors, who may be known mainly to one close community, take on wider celebrity when they are quoted. So while the authors' tweets may perform intimacy and affiliation, emphasising the everyday worlds they share with readers, the 'quotes' treat them as oracles interchangeable with Gandhi, Churchill, Lincoln - or Taylor Swift, Marilyn Monroe, and dozens of motivational speakers.

\section{Authors, the everyday, and celebrity}

Marwick and Boyd (2011) and others have seen Twitter celebrity as a continuum, rather than a sharply defined category, and they have shown that the most followed stars use techniques of engagement developed by microcelebrities. So it is not surprising to find authors who choose to use Twitter also drawing on some of the same strategies of engagement, and also finding their work and words taken up in sometimes uncontrollable ways by fans. The fascination with the lives and statements of selected creative individuals has been a feature of literary response for at least two centuries, as other articles in this collection show. Social media have made it both easier and more difficult for writers to respond to this fascination, while also making visible the tensions around the process of celebrity-making. Authors' own tweets perform a kind of intimacy and develop affiliation, often in fairly subtle ways. But as Harris points out in her 'Manifesto', they then have to deal with the questions, comments, and demands of readers and others who treat them as constantly on tap. The ambivalence of authors about participating in social media may be related to the tension, well explored in celebrity studies, between being ordinary and being special. 
In the case of authors, they are special just because they are held to be above commerce, popular culture, and the demands of popularity. They can open up some aspects of their lives, and find out something about how their work fits in other lives, but part of the author, the part that writes those wonderful books that get all this attention, is supposed to remain inaccessible. 


\section{Notes}

1. For a good example of methodology, see Potts et al. 2014. See also Zappavigna 2012 and Gillen and Merchant 2013; for language on-line more generally see Barton and Lee 2013; Page 2012b, and Page et al. 2014.

2. Readers who want to try corpus analysis themselves might want to use Laurence Anthony's AntConc, which is free and has good on-line tutorials: http://www.laurenceanthony.net/software/antconc/.

3. Details of the reference corpus are at http://thelanguageofblogs.typepad.com/the_language_of_blogs/2012/04/tweetingscience-compiling-a-reference-corpus.html).

4. Log-likelihood is used as a proxy for statistical significance, the measure of the probablility that the result is due to chance. Log-likelihoods over 15.13 correspond to $\mathrm{p}<0.0001$. With such small corpora, I do not base any of my argument on the comparisons of log-likelihoods; I just give the figures to show that the features I am discussing are much more frequent in one corpus than in another.

5. Times are as given in my Twitter feed, and do not reflect the time tweets were actually posted'

6. The algorithm of the CLAWS automatic tagging system depends on running text to determine which tag to assign, and computer scientists have noted that the very noisy stream of Twitter corpora, with many non-lexical and non-standard elements, can make the tagging inaccurate (Derczynski et al, 2013). But I am dealing here with categories where the tags are unlikely to be ambiguous, and the CLAWS output is accurate enough for my purposes.

\section{Acknowledgements}

My thanks to two reviewers, and to the two editors of the journal, whose suggestions greatly improved the paper. Thanks also to Rebecca Braun and Emily Spiers for the invitation to do the workshop on which this paper is based.

\section{Note on contributor}

Greg Myers teaches in the Department of Linguistics and English Language at Lancaster University, UK; his current modules include discourse analysis, research methods, and Language in the Workplace. His books include Matters of Opinion: Talking about Public 
Issues (Cambridge, 2004) and The Discourse of Blogs and Wikis (Continuum/Bloomsbury, 2010).

Department of Linguistics and English Language

Lancaster University

LA1 4YT

g.myers@lancs.ac.uk 


\section{References}

Barthes, R., 1957/1972. The writer on holiday. In: Mythologies, trans. Annette Lavers. New York: Hill and Wang, 29-31.

Barton, D. and Lee, C., 2013. Language online: Investigating digital texts and practices. London: Routledge.

Bennett, J., \& Thomas, S., 2014. Tweet celebrity. Celebrity Studies, 5 (4), 501-503.

Bérubé M., Blum, H., Christopher Castiglia, C., and Spicher, J., 2014. Community Reading and Social Imagination PMLA, 125 (2), 418-425.

Biber, D., Johansson, S., Leech, G., Conrad, S., \& Finegan, E. 1999. Longman Grammar of Spoken and Written English. Harlow: Longman.

Braudy, L., 1997. The frenzy of renown: Fame and its history, $2^{\text {nd }}$ ed. New York: Vintage.

Braudy, L., 2011. Knowing the performer from the performance: fame, celebrity, and literary studies. PMLA, 124 (4), 1070-1075.

Braun, R., 2011. Fetishising intellectual achievement: the Nobel Prize and European literary celebrity. Celebrity Studies, 2 (3), 320-334.

Crown, S., 2015. Patrick Ness: 'You're 10, a refugee in a foreign country. What the hell do you do?' Guardian, 18 December. http://gu.com/p/4fxgy/stw > (accessed 23 September 2016).

Derczynski, L., Ritter, A. Clarke, S., and Bontcheva, K., 2013. Twitter Part-ofSpeech Tagging for All: Overcoming Sparse and Noisy Data. Proceedings of the International Conference on Recent Advances in Natural Language Processing, ACL. Available from: http://www.aclweb.org/website/old_anthology/R/R13/R13-1026.pdf

Dickens, C., 1842. American Notes for General Circulation. London: Chapman \& Hall.

DuBois, J., 2007. The stance triangle. In R. Englebretson (Ed.), Stancetaking in discourse: Subjectivity, evaluation, interaction. Amsterdam: Benjamins.

Dunthorne, J. 2008. Submarine. London: Hamish Hamilton.

Dyer, R. 1979. Stars. London: British Film Institute. 139-182

Flood, A., 2015. Meg Rosoff sparks diversity row over books for marginalised children. Guardian, 13 October. Available from: http://gu.com/p/4d8eg/stw (accessed 23 September 2016) 
Gamson, J. 2011. The unwatched life is not worth living: The elevation of the ordinary in celebrity culture. PMLA, 126(4), 1061-1069.

Gillen, J. and Merchant, G., 2013. Contact calls: Twitter as a dialogic social and linguistic practice. Language Sciences, 35, 47-58

Goffman, E. 1959. The Presentation of Self in Everyday Life. New York: Anchor.

Hoover, D., Culpeper, J., O’Halloran, K., 2014. Digital Literary Studies. London: Routledge.

Kehrberg., A. 2015. 'I love you, please notice me': the hierarchical rhetoric of Twitter fandom, Celebrity Studies, 6:1, 85-99.

Kertesz, A., 1983. On Reading [photobook]. London: Penguin.

Lea, R., 2015. What do writers owe readers in the digital age. Guardian, 20 October. Available from: http://www.theguardian.com/books/2015/oct/20/what-dowriters-owe-readers-in-the-digital-age-joanne-harris-colm-toibin-al-kennedy. (accessed 23 September 2016)

Leypoldt, G., 2014. Singularity and the literary market. New Literary History, 45 (1), 71-88.

Long, E., 2013. Book Clubs: Women and the Uses of Reading in Everyday Life. Chicago: University of Chicago Press.

Mahlberg, M., 2010. Corpus linguistics and the study of nineteenth century fiction. Journal of Victorian Culture, 15 (2), 292-298.

Mahlberg, M., 2013. Corpus Stylistics and Dickens' Fiction. London: Routledge.

Marwick, A.E. and Boyd, d., 2011. To see and be seen: celebrity practice on Twitter. Convergence: the international journal of research into new media technologies, 17 (2), 139-158.

Moran, J. 2000. Star Authors: Literary Celebrity in America. London: Pluto.

Morson, G., 2011. The words of others: From quotations to culture. New Haven, CT: Yale.

Nakamura, L., 2013. 'Words with Friends': Socially Networked Reading on Goodreads. PMLA, 128 (1), 238-243.

Ness, P 2009. The Ask and the Answer. London: Walker Books.

Ohlsson, A., Forslid, T. \& Steiner A., 2014. Literary celebrity reconsidered. Celebrity Studies, 5 (1-2), 32-44. 
Ommundsen, W. (2009). Literary Festivals and Cultural Consumption. Australian Literary Studies, 24 (1), 19-34.

Page, R., 2012a. The linguistics of self-branding and micro-celebrity in Twitter: The role of hashtags Discourse \& Communication 6 (2): 181-201,

Page, R., 2012b. Stories and social media: Identities and interaction. London:

Routledge.

Page, R., Barton, D., Unger, J. W., \& Zappavigna, M., 2014. Researching language and social media: a student guide. London: Routledge.

Petersen, A. 2009. 'We're making our own paparazzi': Twitter and the construction of star authenticity [Special issue]. FlowTV, 9 (14). Available from: http://flowtv.org (accessed 23 September 2016)

Potts, A., Simm, W., Whittle, J., and Unger, U., 2014. Success in digitally augmented activism: A triangulated approach to UK activist Twitter use. Discourse Context \& Media, 6, 65-76.

Price, L., 2000. The Anthology and the rise of the novel: From Richardson to George Eliot. Cambridge: Cambridge University Press [See especially Ch. 3].

Pullman, P. 2000. The Amber Spyglass. London: Scholastic.

Purohit, H., Hampton, A., Shalin, V., Sheth, A., Flach, J., and Bhatt, S., 2013. What kind of \#conversation is Twitter? Mining \#psycholinguistic cues for emergency coordination. Computers in Human Behavior, 29 (6), 2438-2447.

Rankin, I. 2007. Exit Music. London: Orion.

Rayson, P. 2008. From key words to key semantic domains. International journal of corpus linguistics. 13:4 pp. 519-549.

Rojek, C., 2001. Celebrity. London: Reaktion Books.

Rowberry, S. (2016). Commonplacing the public domain: reading the classics socially on the Kindle. Language \& Literature. 25(3): 211-225.

Scannell, P. 2000. For-anyone-as-someone structures Media, Culture \& Society 22 (1): 5-24,

Senft, T. 2008. Camgirls, Community and Celebrity in the Age of Social Networks. New York: Peter Lang.

Swann, J. and Allington, D., 2009. Reading groups and the language of literary texts: a case study in social reading, Language and Literature, 18 (3), 247-264.

Thomas, S. 2014. Celebrity in the 'Twitterverse': history, authenticity and the 
multiplicity of stardom: Situating the 'newness' of Twitter, Celebrity Studies, 5(3), 242-255,

Trilling, L. Sincerity and Authenticity. London: Oxford University Press.

Turner, G. 2004. Understanding Celebrity. Thousand Oaks, CA: SAGE.

Victor, D., 2015. Joyce Carol Oates on Twitter: Is Nothing 'Joyous' in ISIS? New York Times, 23 November. Available from: http://www.nytimes.com/2015/11/24/books/joyce-carol-oates-celebratoryjoyous-islamic-state-twitter.html (accessed 23 September 2016)

Vlieghe, J., Muls, J., and Rutten, K., 2016. Everybody reads: Reader engagement with literature in social media environments. Poetics, 54, 25-37.

Wicke, J. 1988. Advertising Fictions: Literature, Advertisement, and Social Reading. New York: Columbia University Press.

York, L. 2013. Margaret Atwood and the Labour of Literary Celebrity. Toronto: University of Toronto Press.

Zappavigna, M., 2012. The discourse of Twitter and social media. London: Continuum. 